\title{
Plauciano: la amenaza de la DOMUS SEVERIANA
}

\author{
Rafael González Fernández / Pedro David Conesa Navarro
}

(Universidad de Murcia - CEPOAT)

Resumen: En el trabajo presentamos una visión sintética del ascenso y caída de un personaje no demasiado tratado por la historiografía moderna, Plauciano. Sin embargo, tuvo un papel esencial en el acceso al poder de Septimio Severo y también durante los años en que fue prefecto del pretorio, desde 197 hasta enero de 205, cuando murió de forma violenta. De él, dicen las fuentes antiguas que era pariente, pero sobre todo, amigo muy próximo del emperador. Su cercanía a este, más que el propio cargo, le permitió obtener un poder político y económico casi omnímodo, por lo que fue considerado en su tiempo como un cuarto césar. Incluso casó a su hija Plautilla con el heredero al trono, Caracalla. Precisamente sus cotas de poder y su proximidad a Septimio suscitaron recelos y envidias principalmente en el entorno imperial que finalmente provocaron su caída y su muerte inmediata, aunque las fuentes antiguas que escriben estos acontecimientos no coinciden en la narración de los hechos.

Palabras clave: Plauciano, prefecto del pretorio, Septimio Severo, Caracalla.

ABSTRACT: This paper presents a synthetic view of the rise and fall of a little-treated character in modern historiography, Plautian. However, this person played a key role in the accession to power of Septimius Severus and during the years he was Praetorian Prefect, from 197 to January 205, when he died violently. Ancient sources state that he was a patient person, and above all, a very close friend of the Emperor. His proximity to the Emperor, rather than his position proper, enabled him to obtain almost an absolute political and economic power, being considered at 
the time as a fourth Caesar. He even managed that his daughter Plautilla married the heir of the Caracalla throne. It is precisely his power and his proximity to Septimius that raised suspicions and jealousies among the Imperial community, leading ultimately to his downfall and his immediate death; though the ancient sources that describe these events do not necessary coincide.

Keywords: Plautian, praetorian prefect, Septimius Severus, Caracalla.

Mas Plauciano, favorecido que fue de Severo, a quien despeñó por una ventana para que fuese espectáculo del pueblo, decía:

Fui cohete, subí aprisa y, ardiendo con ruido en lo alto, me calificó por estrella la vista. Duré poco y bajé, desmintiendo mis luces en humo y ceniza. ${ }^{1}$

\section{INTRODUCCIÓN}

$\Gamma^{l}$ irresistible ascenso que llevó, en el transcurso de muy pocos años, a EPlauciano ${ }^{2}$ a la cima del poder junto a Septimio Severo y su precipitada caída, culminada con su asesinato la noche del 22 de enero del 205, han convertido a este personaje en una figura emblemática de la mutabilidad de la suerte y del arbitrio del poder imperial. ${ }^{3}$

C(aius) FVLVIVS C(ai) F(ilius) QVIR(ina) PLAVTIANVS, pariente, amigo, y según Herodiano ${ }^{4}$ también amante de Septimio Severo, fue considerado por sus contemporáneos como un personaje sanguinario, temido y odiado. ${ }^{5}$ Visión que se ha seguido manteniendo en la historiografía contemporánea. ${ }^{6}$ Tanto su poder como su muerte, se la debía al emperador al que acompañó durante la última etapa de su vida, que fue además quien lo encumbró al poder. El título, ambiguo: la amenaza de la domus severiana: auge y caída de Plauciano. ¿Quién amenazaba a quién? En cualquier caso el perdedor fue Plauciano.

1. A. DEL Rey (ed.), «Discurso de todos los diablos, o infierno emendado», en F. De Quevedo, Obras completas en prosa, vol. I, t. II, Madrid, 203, p. 521.

2. RE, VII.I, cols. 270-278; PIR F 554

3. M. L. CAldelli, «La titolatura di Plauziano. Una messa a punto», ZPE, 178, 2011, p. 261.

4. Hdn., III, 10, 6 (Historia del Imperio Romano desde Marco Aurelio. Introducción, traducción y notas de J. Torres. Revisada por J. Arce. Madrid, 1985.)

5. Hdn., III, 11, 3 .

6. Véase por ejemplo M. D. SaAvedra Guerrero, «Septimio Severo, Julia Domna y Plauciano: El juego de la traición en la domus aurea», Gerión, 27, 1, 2009, pp. 256-257. 


\section{ORÍGENES Y FAMILIA}

La gens Fuluia de la ciudad de Lepcis está bastante bien documentada. Incluso se constata su existencia en la ciudad antes que los Septimii figuraran entre las principales familias locales. Unas inscripciones de época augustea (3-2 a. C.) reemplazadas en el teatro de la ciudad ${ }^{7}$ presentan a los Fuluii Lepcitani, según la interpretación ya clásica de P. Romanelli, ${ }^{8}$ cuyo uso serviría para marcar la diferencia con los Fuluii itálicos, sin embargo según F. Chausson esta explicación es bastante incierta. ${ }^{9}$ Se conocen diversos testimonios epigráficos de personajes de esta familia. ${ }^{10}$ Sabemos que se relacionaron a través de diversos matrimonios con los Plaucios, una poderosa estirpe de Lepcis en el siglo II. ${ }^{11}$ A. Birley propone además matrimonios mixtos con los Marcios. ${ }^{12}$

Destacamos a Fuluia Pia ${ }^{13}$ hija de Fuluius Macer, madre de Septimio Severo, que debió nacer entre el 120-130 y que posiblemente se casó con $P$. Septimius Geta en la década del 140. Esta unión testimoniaría de forma indirecta la importancia de los Fulvios, puesto que Pía pasó a formar parte de una familia en la que destacaban algunos caballeros y quizás también senadores. La familia, bien implantada localmente, estableció su posición con alianzas con algunas de las más importantes gentes leptizanas, como los Granii, los Marcii, o los Plautii.

El testimonio de Herodiano dice que Plauciano «era paisano de Severo, pues era libio como el emperador, y, según algunos, era pariente suyo». ${ }^{14}$ Por tanto Fulvio Plauciano era uno de los Fulvios de Lepcis e hijo posiblemente, de una Plaucia. Pero ¿cuál era la relación familiar entre Septimio y Plauciano? F. Chausson propone considerar a la madre de Severo como hija de una hermana (o prima) del notable de Lepcis, L. Plautius Octavianus. ${ }^{15}$ Así se explicaría el nombre de la hija de Fulvia y hermana de Septimio, Septimia Octauilla y que por un hermano no atestiguado ella fuera la tía de Caius Fuluius Plautianus. Sabemos que una rama de los llamados Fulvios lepcitanos entró en el orden senatorial hacia la mitad del siglo II. ${ }^{16}$ No es raro, por tanto, que estas familias,

7. IRT 320 y 328

8. P. Romanelli, «Fulvi Lepcitanii», ArchClass, 10, 1958, p. 259

9. F. Chausson, «Variétés généalogiques II. Macer auus maternus de Septime Sévère», en G. BonAmente y F. Paschoud (eds.), Historiae Augustae. Colloquium Perusinum, Bari p. 158, nota 31.

10. IRT 291; IRT 415; IRT 416; IRT 572; IRT 596; IRT 705.

11. M. Torelli, «Per una storia della classe dirigente di Lepcis Magna», Rendiconti Accad. Lincei, ser. 8, 28, 1974, pp. 385 ss. Sobre los Plaucios en general puede verse G. Di Vita-Evrard, «Note sur 'trois' senateurs de Lepcis Magna. Le clarissimat des Plautii», en Epigrafia e ordine senatorio I, Tituli 4, Roma, 1982, pp. 453-465.

12. A. Birley, Septimio Severo. El emperador Africano, Madrid, 2012 (1. a edición española), pp. 256 ss.

13. A la que solo conocemos por IRT 415-416; SHA Seu. 1.2

14. Hdn., III, 10, 6-7.

15. F. Chausson, «Variétés généalogiques II...», p. 160.

16. G. Di Vita-Evrard, «Note sur 'trois sénateurs de Lecpis Magna. Le clarissimat des Plautii», Epigrafia e ordine senatorio I (Tituli 4), 1982, pp. 453-465. 
los Plautii, Fuluii, emparentaran entre ellos y también con los Septimii. Si se admite esta reconstrucción Septimio Severo y Fulvio Plauciano serían primos hermanos. ${ }^{17}$ Tampoco se conoce a la esposa de Plauciano y madre de sus dos hijos: Fuluia Plautilla, esposa de Caracalla y C. Fuluius Plautianus Hortensianus cuyo agnomen podría derivar presuntamente del cognomen de la madre: Hortensia. ${ }^{18}$ Sin embargo, en Lepcis no se halla ningún Hortensio. ${ }^{19}$

\section{Su CARRERA}

A pesar de que llegó a ser tan poderoso como el emperador ${ }^{20}$ o quizás por eso, los datos sobre su carrera antes de la llegada a la prefectura del pretorio nos son esquivos. Sirvió lealmente al emperador durante la guerra civil contra Pescennius Niger y Clodius Albinus y el primer testimonio conocido de su cursus es la prefectura de los uigiles, cargo que ejerció con seguridad en el $195 .^{21}$ Si el cargo fue desempeñado desde el 193, como pretenden algunos autores es algo que no puede demostrarse. Según F. Grosso ${ }^{22}$ habría sido nombrado por Didius Iulianus a partir de una interpretación no confirmada de un texto de D. C. Considerando esa temprana fecha, también podía haber sido nombrado por Pértinax, o incluso por el propio Septimio Severo..$^{23}$ En cualquier caso la discusión sobre la carrera de Plauciano anterior al 195, no estaría fundamentada sobre ningún documento conocido y aceptado. ${ }^{24}$ Se le ha intentado identificar con un personaje anónimo (su nombre fue borrado), que aparece en una inscripción de Lepcis Magna, para sus editores, J. M. Reynolds y J. B. WardPerkins podría ser Plauciano. ${ }^{25}$ P. Romanelli acepta la suposición. ${ }^{26}$ Sin embargo, el contrapunto lo puso H.-G. Pflaum, ${ }^{27}$ quien opina que el contenido de la inscripción no permite apoyar tal hipótesis. A pesar de todo A. Stein ${ }^{28}$ lo incluyó en su magna obra. Asimismo, F. Grosso ${ }^{29}$ consideraba, sin más, que se

17. Por ejemplo A. Daguet-Gagey, Septime Sévère. Rome, l'Afrique et l'Orient, París, 2000, pp. 44 y 205.

18. F. Chausson, «Variétés généalogiques II...», p. 161.

19. A. Birley, Septimio Severo..., p. 323.

20. Dion Casio lo llama cuarto emperador (LXXVI, 15, 2).

21. CIL XIV, 4380. F. Grosso, «Ricerche su Plauziano e gli avvenimenti del suo tempo», Rendiconti dellesedute dell'Academia Nazionale dei Licei, xxin viII, 1-2, pp. 13-17; R. SABlayrolles, Libertinus miles..., pp. 493-495, n. ${ }^{\circ}$ 21. M. Christol, «Comes per omnes expeditiones. L'adulation de Plautien préfet du prétoire de Septime Sévère», Cahiers Glotz, XviII, pp. 217 ss.; M. L. CALDElli, «La titolatura di Plauziano...», pp. 261-262.

22. F. Grosso, «Ricerche su Plauziano ...», pp. 7-13.

23. M. Christol, «Comes per omnes...», p. 217.

24. Veáse la discusión en M. Christol, «Ladulation de Plautien...», p. 218.

25. J. M. ReYNOlds y J. B. WARD-PERKIns, The Inscriptions of Roman Tripolitania (http://irt.kcl.ac.uk/ irt2009/index.html), IRT 572.

26. P. Romanelli, «Fulvi Lepcitanii», ArchClass, 10, 1958, p. 259.

27. H.-G. Pflaum, Les carrières procuratoriennes équestres sous le Haut-Empire romain, París, 1960 1961, pp. 643-644, n. ${ }^{\circ} 238$.

28. Cfr. nota 2.

29. F. Grosso, «Ricerche su Plauziano», p. 16 y nota 5. 
trataba de un pariente de Plauciano. A. Birley ${ }^{30}$ en las distintas ediciones de su famosa biografía del emperador Septimio Severo identifica al personaje de la inscripción con nuestro prefecto. M. Christol lo considera miembro de la gens Fuluia, como no podía ser de otra forma, pero para él no hay ninguna razón que nos pueda hacer considerar que se trata efectivamente de Plauciano. ${ }^{31}$ Presenta una carrera ecuestre ducenaria, praefectus vehiculorum y procurator uicessimae hereditatium. Por tanto, basándonos solamente en los datos ciertos y constatados, se puede considerar que pasó de la prefectura de los vigiles a la del pretorio, cosa que, por otra parte, concuerda perfectamente con los usos establecidos para la época y el cargo. No tendría por qué haber pasado por la prefectura de la annona y no hay huecos en la prefectura de Egipto. ${ }^{32}$ Por tanto, al menos ya desde el 1 de enero del 197 es praefectus praetorio, cargo que desempeñó hasta el día de su muerte. La fecha viene probada por una inscripción ${ }^{33}$ que fue colocada en el cuartel de los equites singulares. Es más que probable que por estas fechas tanto el emperador como Plauciano se encontraran fuera de Roma preparando el enfrentamiento contra Clodio Albino $^{34}$ (muere en Lion, 19/2/197), puesto que Pescennio Níger ya había sido derrotado. Esta inscripción del cuartel de los equites presenta además un problema interesante de restitución en la parte borrada referido a la fecha de la concesión del rango de clarissimus. ${ }^{35}$ Suscribimos la restitución de M. P. Speidel, que acepta M. Christol, pero que no acepta M. L. Caldelli. ${ }^{36}$ Dicha restitución avalaría que el título de clarissimus uir le fue concedido antes de lo que F. Grosso había marcado. Por tanto, ya lo poseería el 1 de enero del 197. Si admitimos esta observación, en el momento en que accede a la prefectura del pretorio gozaría del rango de clarissimus. Lo que evidenciaría que contaba plenamente con la cordialidad del emperador. Las desconfianzas y los castigos

30. A. Birley, Septimio Severo, p. 317.

31. M. Christol, «L'adulation de Plautien», p. 218. Christol además considera que el personaje sufriría damnatio memoriae como consecuencia de sus relaciones con Plauciano y que este podía ser su valedor. Además, compara las líneas que faltan de la inscripción (las seis primeras) con otra inscripción acéfala de Éfeso (CIL III, 6075=ILS 1366=IK, 13, Ephesos 820) que también haría relación a un personaje relacionado con Plauciano y que por ello sufrió damnatio memoriae. Para las abreviaturas de los corpora epigráficos cf. base de datos Clauss-Slaby (www.manfredclauss.de).

32. Sobre los titulares de la prefectura egipcia véase G. BASTIAninI, «Lista dei Prefetti d'Egitto dal $30^{\mathrm{a}}$ al 299" », ZPE 17, 1975, pp. 262-328; Id., «Lista dei prefecti d'Egitto dal 30ª al 299p. Aggiunte e correzioni», ZPE 38, 1980, pp. 75-89; K. BEYER, Der ,praefectus Aegypti 'im Vergleich mit ritterlichen Statthalterschaften der ,provinciae Caesaris' und, provinciae populi Romani, Siegen, 2010.

33. Una inscripción de Roma $(A E, 1935,156=A E, 1954,83=A E, 1968,86)$. Cf. También M. Speidel, Die Denkmäler der Kaiserreiter. Equites singulares Augusti, Bonn, 1994, pp. 77-79, n. 54.

34. Que muere en Lyon el 19 de febrero del 197. Cf. D. KIEnASt, Römische Kaisertabelle. Grundzüge einer römischen Kaiserchronologie, Damstadt, 2004, p. 161.

35. Veáse nota 15. F. Grosso, «Ricerche su Plauziano», pp. 17-20, opina que en la parte borrada no se puede restituir c(larissimus) u(ir). Sin embargo M. Speidel, Die Denkmäler..., pp. 77-78; Id., Riding for Caesar. The Roman Emperor's Horse Guard, London, 1994, p. 59; M. Christol, «Ladulation de Plautien», pp. 219 ss., acepta la restitución de Speidel.

36. M. L. CAldelli, «La titolatura di Plauziano. Una messa a punto», ZPE, 178, 2011, p. 262 , nota 6. 
vendrían más tarde. El 9 de junio del 197 otra inscripción ${ }^{37}$ presenta, ya sin ningún género de dudas, a Plauciano con el título de $u$ (ir) c(larissimus). En cualquier caso esto significaría no tanto la entrada en el Senado como la adquisición de los privilegios propios del orden senatorial y se habría realizado a partir de la concesión de los ornamenta consularia. ${ }^{38}$ La concesión de este título por los emperadores está más o menos atestiguada en la historia del Imperio romano, sin embargo su adjudicación se vio favorecida a partir de los Antoninos y mucho más con los Severos. Concretamente a partir de Septimio Severo tenemos más testimonios, pero que también entrañan mayor dificultad de interpretación puesto que presentan el problema añadido de simultaneidad en el ejercicio del cargo de prefecto del pretorio y el uso de títulos diversos, uir clarissimus o uir eminentissimus. Durante el gobierno de Severo conocemos los casos de Plauciano; ${ }^{39}$ Q. Maecius Laetus ${ }^{40}$ (colega de Papiniano en el 205, tras la muerte de Plauciano); Cn. Marcus Rustius Rufinus. ${ }^{41}$ Sin embargo, estos títulos no implicaban un acceso a la asamblea senatorial y se haría preciso distinguir entre honor, estatus y función. ${ }^{42}$ Parece que los ejemplos de época severa muestran un abandono de la práctica antonina y probarían una modificación en el cursus. ${ }^{43}$ Los prefectos cuya carrera se conoce aunque solo sea en parte, de época antonina hasta finales del siglo III, pudieron seguir un curso lento o rápido, civil o militar. ${ }^{44}$ Había dos vías principales de acceso, la de los militares, hombres de confianza del príncipe, y una segunda, la carrera civil, procuratoria. Y qué duda cabe, también tuvieron una importancia clave las relaciones personales, de afinidad entre los posibles candidatos y la casa imperial, así como su origen geográfico, en el caso de los severos, africano u oriental. Finalmente el acceso a la prefectura del pretorio dependería del apoyo y fidelidad mostrados en el momento de su acceso al poder. En el 193, Severo impuso a Didio Iuliano como pareja de pretorios a sus adeptos D. Veturius Macrinus $^{45}$ y Flauius Iuuenalis. ${ }^{46}$ De Aemilius Saturninus que fue prefecto junto con Plauciano, entre el 197-199/200, también desconocemos sus actividades anteriores. Según la Vita Getae ${ }^{47}$ parece que Flauius Iuvenalis era

37. CIL VI, $224=$ ILS 2185. Cf. M. Speidel, Die Denkmäler..., pp. 77-79, n. ${ }^{\circ} 55$. A. Chastagnol, $L e$ Sénat romain à l'époque impériale, París, 1992, pp. 136-137 y 407, que la fecha hacia el 200; M. CHRISTOL, «L'adulation de Plautien», p. 220, nota 17. Sobre los ornamenta consularia de Plauciano: D. C. 46, 46, 3-4.

38. S. BENOIST, «Le prince et la société romaine d'empire au $\mathrm{III}^{\mathrm{e}}$ siècle: le cas des ornamenta», Cahiers Glotz, XI, 2000, pp. 309-329.

39. CIL VI 224 (9 de junio de 197).

40. CIL VI $228=$ ILS 2187.

41. CIL XIV, 4389, (210-212).

42. Esto ya lo subrayó F. Millar, The Emperor in the Roman World, Londres, 1992, p. 308, nota 4: «as senatorial distinctions, whose precise content is unclear, but which did not afford actual membership of the senate, such ornamenta illustrate once again the divorce of honour or status and function».

43. S. BENOIST, «Le prince et la société», p. 315.

44. J. P. CORIAT, «Les préfets du prétoire de l'époque sévérienne: un essai de synthèse», Cahiers Glotz, 18, 2007, p. 180 .

45. PIR ${ }^{1}$ V, 361. Fue gobernador de Mauritania Tingitana y después, en el 181-183, prefecto de Egipto.

46. $P^{2} R^{2}, \mathrm{~F}, 300$. No se conoce su cursus anterior.

47. SHA, Geta, 2, 4 . 
todavía prefecto en el 200, por lo que Plauciano habría ejercido el cargo de forma colegiada con Iuuenalis y posteriormente con Saturninus que sucedió a este último. Plauciano, que al parecer se libró de su colega, quedó como único prefecto hasta su muerte, momento en el que Septimio nombró de nuevo a otros dos. ${ }^{48}$ Sabemos por diversas fuentes, y D. C. lo confirma a lo largo de su obra, que la colegialidad normalmente fue respetada. ${ }^{49}$ Según el senador griego, Aemilius Saturninus fue colega de Plauciano hasta que este lo eliminó. ${ }^{50}$ El bitinio insiste sobre el caso revolucionario de Sejano y Plauciano, ${ }^{51}$ que aunque obtuvieron el consulado siguieron manteniendo la prefectura, aunque sus casos eran ligeramente diferentes. Sejano, siendo prefecto, fue designado cónsul junto con Tiberio para el año $31,{ }^{52}$ y fue su nombramiento como cónsul lo que le permitió ingresar en el Senado; Plauciano en el desempeño de su prefectura fue honrado con los ornamenta consularia, lo que le permitió obtener en el 203 un consulado ordinario, junto al hermano del emperador P. Septimio Geta, como si los ornamenta equivalieran a un consulado sufecto efectivo. ${ }^{53}$ Dion denuncia esta práctica, ${ }^{54}$ que se dio durante los reinados de Severo, Caracalla y también Macrino, quien habiendo recibido los ornamentos consulares durante su prefectura con Caracalla, no fue hasta su llegada al poder en el 216 cuando aparece como consul iterum. ${ }^{55}$ Todo en la vida de Plauciano parece estar fuera de orden. Otra característica extraordinaria, por lo insólito, fue su consulado, puesto que su desempeño infringió la tradición de dos formas. ${ }^{56}$ En primer lugar, a pesar de ser cónsul y por eso mismo miembro de pleno derecho del Senado, continuó sin embargo con su cargo de prefecto del pretorio. En segundo lugar, también es digno de mención el orden en la proclamación de los cónsules ordinarios del año 203. Esto era algo que estaba sujeto a una serie de convenciones y tradiciones que

48. Septimio vuelve a la colegialidad del cargo nombrando dos prefectos del pretorio: Quintus Maecius Laetus, que había sido prefecto de Egipto en el 200-203 y Aemilius Papinianus, un secretario imperial con una buena reputación como jurista.

49. S. J. DE LAET, «La préfecture du prétoire sous le Haut-Empire et le principe de la collégialité», Revue belge de philologie et d'histoire, 22, 1.2, 1943, pp. 73-95.

50. D. C., LXXVII, 21, 2.

51. R. W. B. SAlway, «Equestrian prefects and the arward of senatorial honours from the Severans to Constantine», en A. KоLB (ed.), Herrschaftsstrukturen und Herrschaftspraxis. Koncepte, Prinzipien und Strategiender Administration im römischen Kaiserreich. Akten der Tagung an der Universität Zürich 18.20.10.2004, Berlín, p. 121. La comparación de Plauciano con otro conocido prefecto del pretorio, Sejano prefecto de Tiberio, es inevitable. De hecho, D. C. explícitamente los compara y resuelve destacando que Plauciano ejerció un poder superior al que Sejano tuvo con Tiberio (Dion CASIO, LVIII, 14, 1). Y no le falta razón al bitinio. Es más que posible que tales similitudes no pasaran inadvertidas a sus contemporáneos, sobre todo los versados en Tácito. Y no sería aventurado imaginar que tales circunstancias podrían haber contribuido a acelerar las sospechas que al final acabaron con su vida.

52. D. C., LVIII, $4,3$.

53. M. Molin, «Prefécture du prétoire dans l'Histoire Romaine de Dion Cassius», Cahiers Glotz, 2007, 18, p. 209.

54. Sin embargo, no alude a Q. Maecius Laetus, colega en la prefectura con Papiniano, tras la muerte de Plauciano, que recibió una adlectio inter consulares con Caracalla y consul iterum en el 215.

55. D. KienASt, Römische Kaisertabelle, p. 169.

56. R. W. B. SAlWAY, «Equestrian prefects», p. 42. 
se habían mantenido en el tiempo. Entre ellas estaba que, por ejemplo, los miembros de la familia imperial precedieran a su colega si este no lo era, o si se trataba de ciudadanos ajenos a la familia imperial, si el nuevo cónsul lo ejercía por segunda vez precedía a su colega que lo hacía por primera vez. Por lo tanto, en circunstancias normales y siguiendo la tradición, la proclamación debería haber sido P. Septimus Geta II, C. Fuluius Plautianus I. Sin embargo, Plauciano lo trastocaba todo. En el año 203 los dos cónsules ${ }^{57}$ son Caius Flauius Plautianus II y Publius Septimius Geta II. En este caso el segundo no solo había sido cónsul sufecto, ${ }^{58}$ sino que además era el hermano del emperador. ${ }^{59}$ Lo normal hubiera sido que Geta figurara el primero y Plauciano el segundo. No obstante, es posible que la preeminencia del prefecto surtiera efecto a pesar de que no hubiera desempeñado un primer consulado efectivo, puesto que solo le habían sido otorgados consularia ornamenta. ${ }^{60}$ Para un senador corriente era muy rara la iteración de un consulado, teniendo en cuenta que la concesión del consulado era la culminación de la carrera senatorial. Después de todo, los títulos y honores otorgados a Plauciano no son más que la punta del iceberg en relación a la inflación de títulos y honores que fueron concedidos a las prefecturas ecuestres durante la dinastía severiana. ${ }^{61}$ Al final, la ascensión de Plauciano tiene dos vías, por un lado, la acumulación de cargos en su carrera y por otro lado la gran originalidad que presentan las formulaciones epigráficas referidas a este personaje. La singularidad de los títulos y honores recibidos, más bien las expresiones utilizadas, llevaron a F. Grosso ${ }^{62}$ a considerar que se trataba de una «titolatura sovrabbondante e spagnolesca della quale egli si compiacerà in modo grottesco». Precisamente de estos títulos queremos hablar brevemente, ya que aunque tradicionalmente, sobre todo los vinculados con sus relaciones de parentesco con la familia imperial, habían sido fechados a partir del matrimonio de su hija con Caracalla desde abril del 202;63 sin embargo, M. Christol ${ }^{64}$ demostró que estos títulos habrían sido «adquiridos» a partir de los esponsales, en torno al 201, por supuesto en una fecha anterior a la celebración del matrimonio. También a partir de los esponsales Plautilla recibe el título de Augusta. Por lo tanto, a

57. A. Degrassi, I Fasti consolari dell'Impero romano, Roma, 1952, p. 57.

58. En una fecha no precisa.

59. Su carrera aparece reflejada en IRT 541 de forma íntegra, aunque no se consigna este segundo consulado. Tampoco se conoce con exactitud el año de su consulado sufecto.

60. Es el primer caso en la historia del mundo romano que los ornamentos consulares fueron computados como un consulado efectivo. Cf. G. Goyau, Chronologie de L'Empire Romaine, París, 2007, p. 143. Sin embargo, es curioso que Caracalla, que tanto odió a su suegro y lo que había significado, mantuvo la «nueva tradición» de honrar a dos prefectos con ornamentos consulares, que además le sirvieron para obtener un segundo consulado: Q. Maecius Laetus (cos. II en el 215) y T. Messius Extricatus (cos. II en el 217).

61. R. W. B. SAlWay, «Equestrian prefects», p. 123, nota 40.

62. F. Grosso, «Ricerche su Plauziano», p. 32.

63. Según las estimaciones de Daguet-Gagey, el enlace matrimonial se realizó entre los días 9 y 15 de abril. Cf. A. Daguet-Gagey, «Septime Sévère, empereur persécuteur des chrétienes?», Revue des Études Augustinienes, 2001, 47, p. 11.

64. M. Christol, «Lepigraphie de Thugga et la carrier de Plautien», en M. Khanoussi, L. Maurin (eds.), Dougga (Thugga). Études épigraphiques, París, 1997, pp. 127-140. 
partir del 201 Plauciano ya aparece en las inscripciones como un miembro más de la domus severiana, formando parte de la familia tota domus diui$n a .{ }^{65}$ Otros títulos fueron necessarius ${ }^{66}$ necessarius et comes Aug(ustorum); ${ }^{67}$ socer et conocer, ${ }^{68}$ adsumptus inter patricios, ${ }^{69}$ allectus in patricias familias, ${ }^{70}$ omnium praecedentium praef(ectus) excellentisimus ${ }^{71}$ pontifex nobilissimus, ${ }^{72}$ adfinis dominorum, ${ }^{73}$ comes per omnes expeditiones eorum. ${ }^{74}$

Todo esto no fue más que el preludio de su consulado ordinario en el 203. Aparece en las inscripciones como casi un cuarto emperador, ${ }^{75}$ lo que se ha llamado una quasi-monarchic position. ${ }^{76}$

De todas las inscripciones conservadas que hacen referencia a Plauciano, solo una alude a su pertenencia al colegio pontificial. ${ }^{77}$ En dicho epígrafe se hace también mención a Plautilla, a Caracalla y a Severo. La inscripción se fecharía entre abril del 202 por la mención del tercer consulado de Septimio Severo y el matrimonio de Plautilla y Caracalla y enero del 205 por la muerte de Plauciano. Uno de los dedicantes, discípulo de los fictores pontificum podría justificar la alusión a este sacerdocio público representado por Septimio, Caracalla y Plauciano. ${ }^{78}$ Plauciano habría sido incluido en el colegio pontificial en el 202 y hacia el 203 habría ingresado en el de XVuiri s.f., puesto que su nombre aparece junto al emperador y sus dos hijos en las actas de los ludi saeculares del $204 .{ }^{79}$ Puesto que el nombre de Plauciano estaría al inicio del documento, junto a los miembros de la casa imperial y no en el lugar que le correspondería, ya que el resto de miembros ocupan el lugar correspondiente a su cooptación, es más que verosímil pensar en que su adscripción a estos dos colegios fue debido

65. CIL VI 226 (del año 202)

66. CIL VIII 25526 (198-205); AE 1967,537 (199-200); IRT530a=AE1952, 83 (198-205); ILAfr 564 (201-abril 202); CIL XIII 1681= ILS 1328a (Otoño 197/enero 198); CIL XI 1337=ILS 1328 (201-abril 202); CIL V 2821 (inicio 202); CIL XI 8050=ILS 903 (203-enero 205); AE 2005,373, (203-205); IG II/III ${ }^{2} 4216$ (203-enero 205); CILI V 4392, (202-205); CIL II ${ }^{2}$ 5/27 (201-205); CIL VIII, 25526, (198-205); IRT 530a=AE 1952, 83 (198-205); CIL VI 227=ILS 427 (198-205); CIL VI 1074=ILS 456 (202-204); ILAfr 565 (201-abril 202); AE 1906, 25=ILS 9004 (198-205); AE 1903, 282 (Inicios 202).

67. CIL VI 643 (198-205); CIL VI1035=ILS 426 (204).

68. ILAfr 564 (201-abril 202); CIL II ${ }^{2}$ 5/27(201-205); CIL V 2821 (inicio 202); CIL XIV 4392, (202-205); ILAfr 565 (201-abril 202).

69. CIL XI 8050=ILS 903 (203-enero 205).

70. $A E$ 2005,373, (203-205).

71. CIL XI 8050=ILS 903 (203-enero 205).

72. CIL VI1035=ILS 426 (204); CIL VI 1074=ILS 456 (202-204).

73. CIL III $6075=I L S 1366$ (poco antes de 205).

74. CILVI 1074= ILS 456 (202-204).

75. Ya visto por Dion CASio. Cfr. nota 116.

76. R. W. B. Salway, «Equestrian prefects», p. 122.

77. CIL VI, 1974=ILS 456. Según G. AlfÖLDY, «Un’iscrizione di Patavium e la titolatura di C. Fulvio Plauziano», en G. AlföLdy, Städte, Elitenund Gesellscheft in der Galia Cisalpina. Epigraphische- historische Untersuchungen, Stuttgar- Steiner, p. 130 también podría hacer referencia a este sacerdocio la inscripción del arco del Foro Boario (CIL VI, 1035=ILS 426).

78. Veáse el comentario a CIL VI, 1074, p. 4322. J. C. SAQUETE, «La acumulación de sacerdocios mayores públicos de la religión pública romana en época altoimperial», Habis, 37, 2006, p. 282.

79. L. SChumacher, «Die vier hohen römischen Priesterkollegien unter der Flaviern, den Antoninen und den Severen (69-235 n. Chr.)», ANWR II, 16.1, 1978, p. 728 y 735 ss. 
a su cercanía o casi pertenencia a la familia imperial y no a su condición de senador. ${ }^{80}$ Es digno de destacar el hecho de que no aparezca el epíteto maximus, ni siquiera en el caso del emperador. ${ }^{81}$ Según L. Schumacher, Plauciano habría sido cooptado en el colegio de pontífices en el 202 y posiblemente en el 203 habría ingresado en el colegio de XVuiri s.f., puesto que su nombre aparece, junto al emperador y sus hijos, al comienzo de las actas de los ludi saeculares celebrados en el 204. ${ }^{82}$ Plauciano podría añadir a sus cargos y títulos civiles su pertenencia a estos dos importantes collegia religiosos. En el año 204 d. C. el colegio de los XVuiri s.f. estaba formado por 23 sacerdotes, cuatro de los cuales eran miembros de la familia imperial (Septimio, Caracalla, Geta y Plauciano), quedando 19 para los senadores. Los datos de época julio-claudia muestran que el número rondaba en torno a esos 19 senadores más los miembros de la familia imperial ${ }^{83}$. De lo que se puede colegir que Plauciano no aparecería con el resto de senadores, organizados según el orden de cooptación, sino al inicio con el resto de la familia imperial. En el caso del acceso al colegio de pontífices no conocemos los detalles, pero podríamos suponer la misma situación. Por lo tanto, su enorme poder aumentado por las relaciones familiares con la dinastía reinante le permitieron el acceso a estos dos importantes cargos sacerdotales, no a través de una cooptación tras la muerte de alguno de los ocupantes del cargo, sino directamente por su consideración de integrante de la familia imperial.

\section{Plauciano en la Casa imperial: el matrimonio de Plautilla}

En el 202, tras su regreso a Roma después de cinco años de ausencia se celebraron grandes fiestas. Se distribuyeron donativos a la plebe y a la guardia: diez piezas de oro por cabeza. Dion habla de lo complacido que se sentía Septimio con semejante liberalidad; razones tenía: era la suma más grande jamás donada por un emperador. Al parecer la suma ascendió a 200.000 sestercios ${ }^{84}$ A continuación se celebró la boda imperial. ${ }^{85}$ Antonino, con 14 años, recibió como esposa a Fulvia Plautilla, hija de Plauciano. Aunque esta era ya considerada emperatriz, ya que recibió el título de Augusta en el mismo momento que se produjeron los esponsales, como advirtió en su día Christol. ${ }^{86}$

80. J. C. SAQUete, «La acumulación de sacerdotes mayores», pp. 282 y 285. la posición de Plauciano dependieran más del favor imperial que de su puesto en el Estado (Herod., III, 10, 6).

81. El epíteto nobilissimus haría referencia a al prefecto del pretorio y no al cargo de pontifex, como bien demostró H. U. Instinsky, «Zur Entstehung des Titels nobilissimus Caesar», Festschrift für R. Egger, Beiträge zur älteren europäischen Kulturgeschichte I, Klagenfurt, 1952, 99 y ss.

82. L. SChHumacher, «Die vier hohen römischen Priesterkollegien unter der Flaviern, der Antoninen und der Severern (69-235 n. Chr.)», ANRW, II, 16.1, pp. 728 y 735 ss.

83. J. SCHEID, «Les prêtres officiels sous les empereurs julio-claudiens», ANRW, II, 16.1, 1978, p. 618.

84. D. C., LXxvi, 1, 1 y 1, 3-4. Hdn., III, 10, 2.

85. Muchas monedas recogen el acontecimiento. Vid. F. GHEDINI, Giulia Domna tra Oriente e Occidente. Le fonti archeologiche, Roma, 1984, p. 20, nota 78; A. BIRLEY, Septimio Severo..., p. 214.

86. Cfr. nota 64. 
Dion Casio, como senador, asistió a la boda y nos hace una descripción como testigo directo comentando que las nupcias sobrepasaron lo estrictamente regio llegando a tener en algunos momentos de la celebración, elementos propios de la gente bárbara y no civilizada. ${ }^{87}$ Poco después tuvieron lugar las ceremonias propiamente dichas que señalaban los decennalia y las victorias contra los partos, que incluirían sacrificios públicos, juegos y espectáculos para conmemorar dichas victorias.

Otra cuestión inconclusa y que todavía provoca controversias es el hecho de si Plautilla y Caracalla tuvieron descendencia. Algunos eruditos así lo creyeron pero no los historiadores modernos. Ni Dion, ni Herodiano dicen nada. Este último además incide en que Caracalla no compartía lecho ni hogar y que sentía aversión hacia ella. ${ }^{88}$ Parece lógico ante este testimonio pensar en una unión estéril. El matrimonio fue tan breve como trágico. Sin embargo, J. Gagé ${ }^{89}$ presenta un testimonio numismático: Plautilla figura en el reverso de una de sus monedas, con una leyenda Pietas Augg, con un niño en sus brazos. ${ }^{90}$ Aunque esta representación suele relacionarse con la institución de las puellae alimentariae. Pero para Gagé nada justifica esta interpretación, ya que sobre las monedas del siglo ir la leyenda pietas Aug, sin relación con las fundaciones alimentarias, celebra la mayoría de las veces las virtudes familiares y maternales de las emperatrices. Junto al testimonio numismático añade su interpretación de las inscripciones de los ludi saeculares del 204. En primer lugar, en uno de los versos del Carmen saeculare de los ludi comentando que frente a la interpretación primera que una intervención de Lucina solo puede entenderse si se refiere a un nacimiento reciente ilustre. En segundo lugar, argumenta que el nacimiento estaría probado en un pasaje que según él había sido mal interpretado, incluido en la conclusión del informe de los quindecenviros, leído ante el Senado en una sesión, entre marzo y agosto, y en el que se habla de un hijo de Antonino. ${ }^{91}$ Por tanto, el nacimiento de un hijo de Caracalla, habría llegado en la segunda mitad del 203, y a él se referirían tanto las monedas de Plautilla como el canto secular del 204.

Plautilla fue la última, pero también la principal baza de Plauciano. A partir de los esponsales y del matrimonio pasaba a ser una pieza fundamental. Era la clave de la continuidad dinástica, una de las piezas fundamentales del engranaje político de Septimio Severo. De ahí su enorme importancia. En este sentido hemos de decir que durante su corta carrera como Augusta se observan hasta al menos once tipos distintos de efigies monetales, un número sin paralelos en la iconografía imperial..$^{92}$ Como contraste podemos decir que Iulia Domna

87. D. C., LXXvi, 1, 2-3; F. GASCó, Sociedad y cultura en tiempos de los Severos, Madrid, 1988, p. 63. 88. Hdn., III, 10, 5 .

89. J. GAGÉ, «La postérité de Caracalla», Comptes rendus des séances de l’Académie des Inscriptions et Belles-Lettres, 78, 1, 1934, 63-67.

90. H. Cohen, Description Historique des Monnaies Frappées sous l'Empire Romain, IV, p. 248, n. ${ }^{\circ}$ 15-18.

91. J. GAGÉ, «La postérité», p. 65, nota 3.

92. Sh. Nodelman, «A Portrait of the Empress Plautilla», The J. Paul Getty Museum Journal, vol. 10, 1982, p. 105. 
solo tuvo 5 tipos en los 24 años en los que ejerció de Augusta con Severo y después con su hijo Caracalla (194-217).$^{93}$ ¿A qué se pudo deber esto? Pues, sin lugar a dudas, debió ser una campaña propagandística de gran intensidad con un claro objetivo político: fortalecer la posición de la joven Augusta, y, a través de ella, la de su padre.

\section{Las propiedades de Plauciano (bona Plautiani)}

«Plauciano dio a su hija una dote que habría bastado para cincuenta mujeres de rango real». ${ }^{94}$ Las fuentes son coincidentes tanto en señalar sus aspectos negativos como en resaltar sus riquezas. No sabemos a ciencia cierta si las posesiones y bienes de Plauciano procedían de su familia, al menos en parte, o se debieron, que es lo más probable, a sus relaciones con el emperador. Las riquezas debieron ser fabulosas, y aunque no tenemos muy claro de donde procedían exactamente, tenemos pistas. ${ }^{95}$ Cuando Herodiano narra la muerte de Plauciano a la vez nos informa de que el príncipe había contribuido generosamente a enriquecer a su prefecto con la entrega de propiedades confiscadas a sus adversarios aspirantes al trono. ${ }^{96}$ Lo que es seguro es que fueron tan enormes que Septimio tuvo que nombrar tras su muerte un procurator ad bona Plautiani atestiguado en un epígrafe encontrado en Dacia. $^{97}$

Entre sus principales posesiones destacaremos que una parte considerable de los alfares de Roma a principios del siglo III eran propiedad del omnipotente prefecto. El título que presenta Plauciano en casi todos los sellos, con una o dos excepciones al menos en lo que conocemos, era: $p$ (raefectus) $p$ (raetorio) $c$ (larissimus) u(ir) cos II, lo que nos permite fechar su propiedad en un breve periodo entre enero del 203 y enero del 205, puesto que aparece su segundo consulado. Según H. Bloch, ${ }^{98}$ Plauciano, hasta su caída, reorganizó muchas figlinae que habrían sufrido una etapa de crisis en época de Cómodo. Por lo que sabemos en las figlinae Genianae la reorganización se debió a Plauciano. En las Terentianae, el officinator L. Aelius Phidelis que estuvo al servicio de Plauciano, pasó después, conservando su marca de fábrica, al servicio de los nuevos dueños: los dos Augustos. En las Ponticulanae aparecen unos timbres idénticos a los de las figlinae Terentianae caracacterizados por una stella inter cornua luna crescentis, en el periodo del 203-205. De las figlinae Bucconianae

93. Ibidem.

94. D. C., LXXVI, 1, 2.

95. T. KотUla, T. Lewicki, «Un témoignage d'al-Bakrī et le problème de la ratio privata sévérienne en Tripolitaine», Antiquités africaines, 22, 1986, p. 263.

96. Hdn., III, 10, 6.

97. H.-G. Pflaum, Les carrières procuratoriennes..., II, pp. 691-694, n. ․ 257; CIL III, 1464 (p. 1407)= D $1370=I D R-3-2,100=I L D 241=$ RHP 276=AE 1980, 758.

98. H. BLOCH, I bolli laterizi e la storia edilizia romana. Contributi all'archeologia e alla storia romana, Roma, 1968, pp. 292-298. 
otros sellos (inéditos según Bloch) confirmarían que el prefecto, al menos en parte, era dueño de las figlinae Domitianae maiores y minores. Probablemente en las Domitianae minores el officinator era su liberto Fuluius Primitivus, quien pasó después de la caída de su patrono, como Lanio Festo en las Genianae, a los dos Augustos. También de las figlinae Domitianae, Veteres, Nouae, Faorianae, está constatada la propiedad del prefecto y después su paso a los dos Augustos. De las figlinae poseídas por Plauciano, todas excepto las Genianae habían sido anteriormente de posesión imperial..$^{99}$ De los talleres imperiales, de los que hay sellos de este periodo, solamente las Marcianae y Oceanae no pertenecieron al prefecto. Tras la muerte de Plauciano todas ellas, como sus bienes en general, pasaron de nuevo a la familia imperial, a la ratio priuata del emperador. Esto demostraría que el emperador había renunciado a una serie de grandes y fructíferas propiedades en beneficio de su imprescindible ${ }^{100}$ Plauciano, ${ }^{101}$ esto, como tantas otras cosas que ya hemos visto, nos muestra bien a las claras cómo fue la relación entre Septimio y Plauciano en los buenos tiempos.

Productor y comerciante de aceite. Entre las evidencias también tenemos que destacar los sellos aparecidos en ánforas tripolitanas III que constituyen una fuente esencial para el estudio de la producción y del comercio del aceite tripolitano entre los siglos III y IV. ${ }^{102}$ En algunas aparece el sello CFPPP: $C$. Ful(ius)Plaut(ianus) Pr(aefectus) Pr(aetorio). Han aparecido en Israel, ${ }^{103}$ en el monte Testaccio y otros lugares. Se fecharían entre el 197-205. Su damnatio memoriae testimoniada por numerosas supresiones sobre los epígrafes, está atestiguada también por la anulación de su nombre en un sello de ánfora. ${ }^{104}$ Aunque no disponemos de informaciones sobre la propiedad de la tierra en Tripolitania, podríamos suponer que los sellos que marcan las ánforas no solo se refieran al dueño del alfar, sino también al propietario del fundus en que se producía el aceite y en el que también se encontrarían los talleres para la producción de las ánforas. Por lo tanto, a pesar de lo arriesgado de la hipótesis, podríamos aventurar que, como en las producciones imperiales, Plauciano era dueño de la tierra en la que se producía el aceite, así como los alfares que fabricaban ánforas para su transporte. El hallazgo en la costa israelí, concretamente en Raphia, entre Egipto y Palestina, nos puede hacer suponer que la actividad económica originada en los campos tripolitanos de Plauciano no solo tenía sus puntos de venta en la urbe, sino que también en el mercado libre interprovincial. Hay que tener en cuenta que Plauciano estuvo en Egipto con Severo y toda la corte en el 199-200. Teóricamente podríamos pensar en una especie «annona privata» del prefecto del pretorio, que proveería

99. P. SEтÄLÄ, Private Domini in the Roman Brick Stamps of the Empire: A Historical and Prosopographical Study of Landowners in the District of Rome, Helsinki, 1977, p. 122.

100. Tomo el epíteto del malogrado F. GAscó, Sociedad y cultura, p. 60.

101. P. SetäLÄ, Private Domini in the Roman Brick, p. 126.

102. D. MANACORDA, «Testimonianze sulla produzione e il consumo dell'ollio tripolitano nel III secolo», Dialoghi di Archeologia, 9-10, p. 564.

103. S. BEN ARICH, «Survey between, Raphia and the brook of Egypt. B. The finds», Atiqot, 7, 1974, p. 93. 104. CIL XV, 206. 
autónomamente al abastecimiento del propio séquito. ${ }^{105}$ No sabemos si el ánfora de Raphia se trata de un hallazgo aislado. ${ }^{106}$

Otra pequeña evidencia sobre posibles fuentes de riqueza de Plauciano apareció en Lepcis Magna en donde se descubrieron un par de bloques de mármol negro del que desconocemos su cantera de origen. ${ }^{107}$ Este tipo que no era muy abundante en el mundo romano era extraído en diversos lugares pero no en grandes cantidades y algunas canteras parecen haber funcionado para el mercado local. Entre otras conocemos algunas de Melos, Lesbos y Laconia. ${ }^{108}$ Fuera de Grecia, Plinio ${ }^{109}$ cita a Varrón para referirse a una piedra negra que por el contexto podría ser mármol y que procedía de África. Asimismo existieron algunas explotaciones en la Galia. Por otro lado, no hay que nos haga pensar que este mármol podría haber sido importado. Presentan un epígrafe ${ }^{110}$ no oficial con instrucciones para enviar desde la cantera al lugar donde el mármol debía ser utilizado: Lepcis. El carácter no oficial del texto lo preservó precisamente del borrado del que fueron objeto todos los textos oficiales. No se trata de inscripciones oficiales sino de indicaciones (órdenes de entrega), conservadas porque fueron grabadas en una cara que no fue trabajada. ${ }^{111}$ Lo único que demuestra la inscripción es que los bloques fueron enviados siguiendo las órdenes de Plauciano, pero no especifica si él era propietario de la cantera o simplemente era un cliente que había hecho un pedido. Es verdad que desde los primeros tiempos del Imperio hay una tendencia a que las canteras más importantes pasen a control imperial. ${ }^{12}$ No sería descabellado pensar que él era el propietario de una (o más canteras) y que ordenó el envío para la construcción de la Basílica Severa y del Foro. Aunque no tenemos ninguna noticia sobre una normativa que pudiera regular la explotación de una cantera por parte de un particular o una ciudad, es posible que muchas de ellas y, sobre todo, la gran mayoría de las que surtían un mercado local podrían haber permanecido en manos privadas. ${ }^{113}$ Tenemos ejemplos como el de Herodes Atticus y las canteras de mármol pentélico. Como Herodes, Fulvio Plauciano, que sabemos que estaba interesado en el suministro de materiales de construcción, no sería descabellado pensar que él podía ser propietario de una (o más canteras) y que ordenó el envío de un cargamento de mármol negro a Lepcis Magna para la construcción de la Basílica Severa y del Foro.

105. D. MANACORDA, «Testimonianze sulla produzione», p. 599, nota 253.

106. S. BEN ARICH, «Survey between, Raphia», p. 14 afirma: «Most of the amphorae originate in Africa Poconsularis and Tripolitania», pero no revela la cantidad de los hallazgos de Raphia.

107. J. WARD PERKINS «Tripolitania and the Marble Trade», JRS, 1951, 41, 1-2, pp. 90-91.

108. Ibidem, p. 91.

109. Plin., N.H., xxxvi, 135.

110. IRT 530 a y b.

111. J. Françols, Les curateurs des cités dans L'Occident romain. De Trajan à Gallien. Études prosopographiques, París, 1986, p. 184.

112. J. WARD PERKINS, «Tripolitania and the Marble», p. 92, nota 31.

113. Ibidem, p. 92, nota 32. 
¿Domus de Plauciano? Tras el hallazgo de dos fistulae aquariae en el Quirinal, en una extensa domus, se planteó la posibilidad de que dicha vivienda perteneciera a Plauciano. ${ }^{114}$ Entre las estructuras devastadas por un incendio, se recuperaron muchas estatuas, fragmentos arquitectónicos de diversas procedencias y los dos fragmentos citados de conducción de plomo. ${ }^{115} \mathrm{Sin}$ embargo, en los últimos tiempos se duda de esa posibilidad, fundamentalmente porque la presencia de dichas fistulae no probaría la propiedad y además los niveles de principios del siglo III no presentan los rasgos de una casa de uno de los hombres más ricos del Imperio. Además, en el sello, junto al nombre de Plauciano, con el título de prefecto del pretorio y clarissimus uir, aparecían los nombres de los procuratores, característica que le acerca significativamente a las del emperador y que testimonia cómo la sed de poder del prefecto lo habría llevado de forma muy evidente a considerarse en la misma posición junto al príncipe. ${ }^{116} \mathrm{~W}$. Eck ha reinterpretado los sellos, puesto que llamaba mucho la atención la presencia de procuratores y manifiesta que la fórmula corresponde a las de las conducciones imperiales. En este caso parece muy probable que Plauciano, como en otros ámbitos económicos, se encargara también del aporte de agua. Se trataría de otro ejemplo más del inmenso poder económico y político que llegó a desplegar el «cuarto césar». Por lo tanto, los hallazgos del Quirinal se han de conectar con la actividad de Plauciano como concesionario de agua ${ }^{117}$ y no como propietario de una uilla. ${ }^{118}$

\section{LA MUERTE DEL FAVORITO. CAÍDA DE LA CAMARILla y DEL LiNAJE DE Plauciano}

Los autores antiguos y también los modernos suelen coincidir en que, como en el caso de otros prefectos del pretorio como Sejano, Perenne o Cleandro, Plauciano murió víctima de su ambición. ${ }^{119}$ La Fortuna abandonó a Plauciano que empezó a declinar con el fallecimiento del hermano del emperador. Posiblemente las revelaciones de Geta, en su lecho de muerte, si bien no lograron convencer del todo a Septimio, sí contribuyeron a crear un clima de desconfianza que llegaría a su punto álgido la noche del 22 de enero del $205,{ }^{120}$ cuando

114. P. L. TuCCI, «Tra il Quirinale e l'Acquedotto Vergine sulla pianta marmorea severiana: i frammenti 538a-o», Analecta Romana Instituti Danici, xxıII, 1996, p. 31.

115. Con el sello FVLVI PLAVTIAN PR PR C V Cfr. E. M. STEINBy, «Le fistule di Fulvius Plautianus» en AA. VV., Epigrafia della produzione e della distribuzione, Roma, 1994, pp. 659-660.

116. Ch. Bruun, The Water Supply of Ancient Rome: a Study of Roman Imperial Administration, Helsinki, 1991, 229-230. D. C., LXxvi,15,2, en el que Plauciano es parangonado explícitamente a un cuarto emperador.

117. W. ECK, «Domus: C. Fuluius Plautianus», LTUR II, Roma, 1995, p. 106.

118. E. Lissi Caronna, ibidem, 105-106.

119. L. Hautecoeur, «C. Fulvius Plautianus et le préfeture du prétoire», Mélanges Cagnat, París, 1912, p. 187.

120. El día y el mes de la muerte de Plauciano solo aparece en el Chronicon Paschale (L. A. Dindorf, París, 1860, col. Patrologia Graeca, 92, p. 496. Sin embargo, equivocadamente el año que da para su muerte 
en Roma se estaban celebrando los ludi palatini. Asimismo, también contribuirían las presiones de Caracalla, exasperado por la insolencia de su mujer y la inquisición ejercida por Plauciano en todo lo que hacía el príncipe heredero. ${ }^{121}$ Igualmente adivinamos, en la sombra, la presencia de Iulia Domna. ${ }^{122}$ Sobre el papel de la emperatriz y su enfrentamiento con Plauciano solo unas pocas líneas. Evidentemente su relación fue de mal en peor. La situación llegó a tal punto que según Dion Casio el prefecto finalmente persuadió a Severo y fue acusada de adulterio. ${ }^{123}$ La Historia Augusta se hace eco de estas tensiones: se la presenta como adúltera, ${ }^{124}$ cometiendo incesto con Caracalla. ${ }^{125} \mathrm{La}$ acusación fue de traición, en concordancia con el desarrollo jurídico de época imperial, en el que el adulterio de una mujer de la familia imperial podía ser considerado de esa forma. ${ }^{126} \mathrm{La}$ emperatriz finalmente fue absuelta, aunque el prefecto llevó el proceso al extremo de torturar a mujeres libres para obtener evidencias contra la emperatriz. ${ }^{127}$ Ante este panorama la vida en la corte no debió ser en absoluto agradable y parece que fue en estos momentos cuando se «autoexilió» (si es que esta separación no fue ordenada por el propio Septimio Severo) hacia un modo de vida alejado de la corte, orientada hacia el estudio en general y la filosofía en particular. ${ }^{128}$ Posiblemente durante este tiempo aumentó su rencor hacia el prefecto e hizo incrementar el de su hijo mayor hacia su esposa y suegro. ${ }^{129}$ En las ceremonias de los ludi saeculares del 204 parece haber ya muestras y signos muy evidentes de reconciliación entre Septimio Severo y su mujer Iulia Domna, que coincide con el inicio del declive del prefecto.

Plauciano cuyo poder fue enorme a partir del año 200 se encontró enfrentado a Julia Domna y también a sus hijos. ${ }^{130}$ La emperatriz se vio tremendamente afectada por el aumento de poder de Plauciano y sus difíciles relaciones con

es justamente el de su consulado junto con Publio Septimio Geta, hermano del emperador, es decir, el 203. No obstante, la crítica no ha dudado en dar por válido el día y el mes: Plautianus consul ex a(nte) d(iem) XI Kalendas Februarii necatus est. L. Hautecoeur p. 197, en su obra cita otras fechas propuestas por otros historiadores, V. Duruy y M. de Ceuleneer proponen el 23 de enero de 204; Lenain de Tillemont el 22 de enero de 205 que es la fecha comúnmente aceptada. Finalmente, Hautecoeur se decanta por esta última.

121. D. C., LXxvi, 3, 1.

122. Sobre el enfrentamiento entre Iulia y Plauciano se ha escrito mucho. Normalmente se pone el acento en la participación oculta de Iulia en la muerte del prefecto. Entre otros: CH. GorRIE, «Julia Domna's building patronage, imperial family roles and the Severan revival of moral legislation», Historia, 53, 1, 2004, pp. 61-72; M. D. SaAvedra Guerrero, «Imagen, mito y realidad en el reinado de Septimio Severo. Julia Domna y la virtus en la familia imperial», Athenaeum, 2006, pp. 95-104; J. LANGFORD, Maternal Megalomania. Julia Domna and the Imperial Politics of Motherhood, Baltimore, 2013.

123. D. C., LXxv, 15.

124. SHA, Seu., XviII, 8.

125. SHA, Seu., xxi, 7; Car., x 1-4; Aur. Vict. Epit. xxi, 3.

126. Tácito, Ann. II, 50.

127. Esclavos podían ser torturados en un juicio por traición: D. C., XLVIII, 4, 8

128. D. C., Lxxv, 15.

129. D. C., LXXVI, 3.

130. F. GAscó, Sociedad y cultura, p. 62, nota 25, plantea que la rivalidad surgió por alcanzar la mayor influencia posible sobre Severo. Esta tensión se pudo agravar por la persecución feroz de Plauciano sobre los partidarios de Nigro (SHA, Seu., xv, 4) y sobre todo por las desmesuras en las provincias orientales muy estimadas por la emperatriz (D. C., Lxxv, 14, 3-5). Cfr. F. Grosso, «Ricerche su Plauciano», pp. 34 y ss. 
este, ${ }^{131}$ que, según Dion Casio, la obligaron a dedicarse al estudio de la filosofía y a pasar los días en compañía de los sofistas. ${ }^{132}$

La consecuencia fue fundamentalmente que el entorno sirio de la emperatriz, y ella misma, ocuparon un papel fundamental en el gobierno del Imperio.

Posiblemente el año 203 marca el punto máximo de su ascensión y el inicio del declive. Una erupción del Vesubio, de la que Dion Casio fue testigo en su casa de Campania, y que tuvo lugar poco tiempo antes de la muerte de Plauciano fue considerada un signum. ${ }^{133}$ Durante la estancia en África (probablemente en la primera mitad del 203), concretamente en Lepcis, se produjo la primera grieta seria en las relaciones entre Septimio y Pluciano. Dion y la Historia Augusta nos dan algún dato, aunque no terminan de coincidir. Según Dion, Septimio se sintió irritado por el número de estatuas erigidas en honor a Plauciano. La Historia Augusta especifica que su enfado se debía a que «Plauciano había colocado su propia entre las de sus parientes y allegados». Lepcis era la cuna del clan y las imágenes allí estarían omnipresentes. En cualquier caso Septimio ordenó fundir algunas estatuas de bronce y parece que se difundió el rumor de que había sido destituido. La noticia corrió y algunos cargos oficiales procedieron a actuar en consecuencia. Fue el caso del gobernador de Cerdeña, Raucio Constante que derribó estatuas del prefecto y poco después sufrió las consecuencias ya que fue juzgado y castigado. La Historia Augusta habla incluso de que Septimio declaró hostis publicus a Plauciano, pero luego se calmó. La brecha se había cerrado, pero por poco tiempo. Pues bien, como decimos, la diosa Fortuna que tan propicia se había mostrado hasta entonces, empezó a volverle la espalda sobre todo a partir del fallecimiento del hermano del emperador en el 204. Posiblemente las revelaciones de Geta, en su lecho de muerte, si bien no lograron convencerle del todo, sí contribuyeron a crear un clima de desconfianza que llegaría a su punto álgido la noche del 22 de enero del 205. Asimismo, también contribuirían las presiones de Caracalla, exasperado por la insolencia de su mujer y la inquisición ejercida por Plauciano en todo lo que hacía el príncipe heredero, según el testimonio de Dion. A la vez, adivinamos, en la sombra, la presencia de Iulia Domna. En torno a año y medio duró la tranquilidad y finalmente una noche a finales de enero del 205 nos encontramos ante una escena que seguramente hubiera firmado W. Shakespeare. ${ }^{134}$

La versión transmitida por Herodiano nos presenta a Plauciano como instigador del asesinato del emperador y su hijo mayor, para lo que urdió el siguiente plan. Le ofreció a Saturnino, tribuno de los pretorianos, la prefectura.

131. Existe una tradición adversa a Iulia Domna, posiblemente originada a partir del enfrentamiento con el prefecto: se la presenta como adúltera (SHA, Seu., xvIII, 8), cometiendo incesto con Caracalla (SHA, Seu., xxi, 7; SHA, Car., x, 1-4; Aur. Vict., Epit., xxi, 3).

132. D. C., Lxxv, 15, 6-7. Además, según Dion en tiempos de su hijo Caracalla, la dedicación de la emperatriz a estos temas fue totalmente voluntaria y muy intensa (LXXVII, 18, 3).

133. D. C., LXXVI, 2.

134. F. Missere Fontana, «Numismatica delle Auguste: L'esempio di Plautilla», Memorie dell'Accademia Italiana di Studi Filatelici e Numismatici, v, 1993, 2, p. 36. 
Este le pidió órdenes por escrito y Plauciano se las dio y directamente se las llevó y mostró a Severo. El emperador no dio demasiado crédito a sus palabras pensando que era un montaje de su propio hijo. El propio emperador hizo llamar a palacio al prefecto para mantener una reunión con él. Caracalla que previamente había hecho ocultar a los centuriones, golpeó a Plauciano cuando vio que su padre dudaba ante las justificaciones de aquel y lo habría matado de no haberlo impedido el propio emperador; pero los centuriones que salieron de su escondite le dieron muerte finalmente. La iniciativa partió del propio Saturnino, compelido a actuar ante el peligro de ser ajusticiado. Argumentó que podría hacer venir a Plauciano a través de una persona de confianza tras informarle de que el trabajo que había encargado se había llevado a cabo. Así, Plauciano se dirigió finalmente al palacio. Al llegar el tribuno le saludó como nuevo emperador. Severo había dado órdenes a sus hombres para que lo detuvieran. Cuando vio al emperador vivo comprendió que había sido engañado y que su plan había fracasado e intentó defenderse, aduciendo que se trataba de una conspiración contra él mismo. Severo le echaba en cara su acto y Plauciano le recordaba su amistad y lealtad. Cuando Plauciano parecía estar convenciendo al emperador, se descubrió que vestía coraza y Caracalla dio orden de darle muerte al tribuno y a los soldados que le acompañaban.

Dion habla de maquinación de Caracalla. ${ }^{135}$ Lo considera responsable directo y según su versión Caracalla persuade a Saturnino y a otros dos para que testifiquen ante Severo que el prefecto quería asesinarlos. El emperador después de oír a su hijo decide confrontar a los acusadores con el propio Plauciano. Cuando llegó al palacio y se le interrogó, lo negó todo pero Caracalla dio la orden a los guardias de que lo mataran. Hay una escena que no quiero dejar de mencionar en Dion y es cuando alguien, anónimo, corre hacia Julia exclamando «aquí tienes a tu Plauciano» exhibiendo pelos de la barba del prefecto muerto, que previamente le había arrancado. ${ }^{136}$ Plauciano fue inmediatamente ejecutado y de creer a Herodiano su cuerpo fue arrojado a la calle por una ventana y habría sido públicamente profanado en lo que constituiría claramente también un acto de poena post mortem. ${ }^{137} \mathrm{Sin}$ embargo, según Dion Casio, el emperador recuperó el cuerpo y lo hizo enterrar, lo que cuadraría más con el contexto posterior. La versión del biógrafo de la Historia Augusta difiere de las dos anteriores. Según su autor el responsable es el propio emperador. Quiere acabar con él y lo declara enemigo público en el momento en que se da cuenta de la ambición sin límites del prefecto. Tras la muerte de Plauciano, el propio emperador, que al parecer no investigó sobre la acción de Plauciano, se limitó a enviar al exilio a su nuera Plautilla junto

135. D. C., LXXVI, 3, 1.

136. El pelo, en este caso de la barba, que representaría la cabeza como sede de la dynamis. Cfr. B. KÖтTING, «Haar», RAC, xıII, 1986, 178-203, con bibliografía.

137. Hdn., III, 12, 12. Cf. E. R. VARNER, Mutilation and Transformation. Damnatio memoriae and Roman Imperial Portraiture, Boston, 2004, p. 161. 
a su hermano Hortensiano, en contra de la idea de Caracalla que pretendía condenarlos a muerte. ${ }^{138}$

De las tres versiones, la de Herodiano parece la menos creíble. Es poco probable que un hombre tan próximo al emperador y que se había mantenido fiel desde largo tiempo, de pronto quisiera alcanzar el poder acabando con el emperador y con su heredero. Podríamos aducir que si hubiera tenido éxito esta supuesta conspiración, aún quedaban Iulia Domna y Geta. Además, una conjura de este tipo habría requerido la participación de más gente, sin embargo el historiador no nos da más datos. Otra cuestión que refuerza la debilidad de la teoría que expuso Herodiano es el hecho de que los hijos de Plauciano no fueron ejecutados de inmediato, como hubiera sido lo propio sino que, por el contrario, son enviados al exilio.

A nuestros ojos la versión de Dion Casio parece más convincente. Según el bitinio la intriga fue planeada por Caracalla para asesinar a su propio suegro. Sin embargo, aquí podemos plantear alguna duda. La principal es que el joven e inexperto heredero pudiera haberlo llevado a cabo solo, sin ayuda de nadie. En este sentido, la Historia Augusta, achaca la responsabilidad directa al emperador, que se muestra decidido a intervenir al ser consciente de la mutua aversión entre Caracalla y Plauciano. El emperador podría haber tenido en cuenta los enfrentamientos futuros entre ellos, si él desaparecía, máxime que otro posible valedor del príncipe, Septimio Geta había muerto hacía poco y además cargando contra el prefecto.

No obstante, las versiones no son absolutamente excluyentes entre sí. Aun a riesgo de redundar en la obviedad, tenemos las fuentes que tenemos y dicen lo que dicen, de tal forma que la interpretación al final siempre va a depender de las «intuiciones» de cada historiador. En este sentido exponemos las más recientes e importantes. A. R. Birley, reconoce como más verídica la de Dion Casio, que expone además la sesión del Senado en la que sus miembros fueron informados de la muerte del prefecto, aunque la causa verdadera sigue siendo una incógnita. T. Kotula ${ }^{139}$ manifiesta que todas las versiones conservadas contienen en mayor o menor medida ecos de la propaganda imperial, hostil al prefecto. Para el autor polaco el principal instigador en contra del poderoso prefecto, eso sí, en la sombra, podría haber sido la emperatriz Iulia Domna, provocada por sus ansias de poder y su arrogancia. J. Spielvogel ${ }^{140}$ destaca la distorsionada imagen del complot de Plauciano en las fuentes, recogiendo a su vez la opinión de E. Hohl. ${ }^{141}$ Este autor reconoce que las actuaciones represivas llevadas a cabo por la casa imperial, con Severo a la cabeza, tras la caída de Plauciano parecen ir más que contra presuntos conspiradores, más bien como

138. SHA, Seu., 14, 5 .

139. T. Котula, Septymiusz Sewerus. Cesarz z Lepcis Magna, Wroclaw, 1987, pp. 80 y ss., citado en D. Окоќ, Septimius Severus et senatores Septimius Severus' Personal Policy Towards Senators in the Light of Prosopographic Research (192-211 A.D.), Szczecin, 2012, p. 57.

140. J. Spielvogel, Septimius Severus, Darmstad, 2006, p. 117

141. E. HoHL, Herodian und der Sturz Plautians, Berlín, 1956 
acciones preventivas contra senadores que en un futuro pudieran suponer un problema para la permanencia de la domus severiana. Dagey considera parcial la versión de Dion Casio y haciendo suyo el relato de Herodiano, plantea la posibilidad de que Plauciano realmente quisiera asesinar a Severo y a Caracalla. David Potter presenta a Plauciano como víctima de una conjura urdida por Caracalla y que el propio Dion Casio habría comprendido al oír al emperador dar explicaciones y justificar la muerte de su prefecto en la sesión del día siguiente en el Senado. La muerte de este habría sido aceptada por Septimio Severo como acto del destino. ${ }^{142}$ Por lo tanto nos parece que ninguna de las tres versiones de las fuentes literarias son excluyentes y que dependerá de cada investigador el decantarse por una u otra o por aspectos parciales de alguna de ellas. Inmediatamente tras su muerte, el Senado difunde una versión pública, políticamente correcta, ${ }^{143}$ que acusa a Plauciano de tramar una conjura para asesinar a Septimio Severo y al heredero Caracalla. Encontramos ecos de esta versión más de un siglo y medio después en Amiano Marcellino, cuando, refiriéndose a Valente dice: «más opresor que Plauciano que, siendo igualmente prefecto en la época de Septimio Severo, y creyéndose por encima de los demás mortales, hubiera causado una revuelta general si no hubiera sucumbido ante el golpe vengador de una espada». ${ }^{144} \mathrm{Y}$ más adelante: «Y, en cuanto a Severo, ya en plena vejez sufrió un ataque por sorpresa a manos del centurión Saturnino, que había sido empujado a ello por el prefecto Plauciano. Y estuvo a punto de ser asesinado cuando yacía en su lecho, aunque le salvó su hijo aún adolescente». ${ }^{145}$

La primera consecuencia directa fue una damnatio memoriae. ${ }^{146}$ Se ha hablado incluso de que post mortem hubiera sido declarado hostis publicus, ${ }^{147}$ pero esto no se ha podido demostrar. Su nombre desapareció de los documentos oficiales, las inscripciones fueron «amartilladas», las estatuas abatidas y fundidas, los relieves arrasados, y, finalmente, sus bienes confiscados. ${ }^{148} \mathrm{Se}$ realizó una purga en la que se incluyeron no solo a personas cercanas a Plauciano sino también a otros que no tenían nada que ver con él. ${ }^{149}$ El clima sería

142.D. Рotter, «Septimio Severo», en A. Barrett (ed.), Vida de los Césares, Barcelona, 2009 (Oxford, 2008), pp. 353-354.

143. A. Daguet- Gagey, «C. Fulvius Plautianus, hostis publicum Rome, 205-208 après J.-C.» en M. H. QuET (ed.), La «crise» de l'Empire romain de Marc Aurèle à Constantin. Mutations, continuités, ruptures, París, p. 75.

144. АMm. Marc., 26, 6, 8.

145. AMM. MARC., 29, 1, 17.

146. E. R. VARner, Mutilation and Transformation..., p. 156: El periodo de la dinastía severiana marca una coyuntura crítica en la historia de la damnatio memoriae. Durante los 42 años de la dinastía (193-235) la damnatio fue practicada contra numerosos miembros de la familia imperial, así como contra emperadores o candidatos al trono caídos. La lista es larga: Didius Iulianus, Pescennius Niger, Clodius Albinus, Plautianus, Plautilla, Geta, Macrinus, Diadumedianus. Elagabalus y Iulia Soemias. Severo Alejandro y Julia Mammea sufrieron una suerte de damnatio espontánea.

147. A. Daguet-GageY, «C. Fulvius Plautianus. Hostis publicus...», p. 75, nota. La autora se basa, entre otros, en los sucesos producidos tras la muerte de Cómodo.

148. Cfr. nota 66.

149. D. Око́, Septimius Severus et Senatores..., pp. 59-60. 
muy similar al desarrollado ocho años antes con la eliminación de Clodio Albino y sus partidarios. El año 205, por tanto, comenzó con la separación del poder de los hijos del prefecto. Severo no consintió su eliminación física. Fuluia Plautilla, hasta ese momento esposa del heredero y su hermano Caius Fuluius Plautius Hortensianus fueron enviados al exilio a las islas Lípari. ${ }^{150}$ Sin embargo, muy poco tiempo después de la muerte de Severo, ${ }^{151}$ Caracalla ordenaría matar a los dos hermanos. ${ }^{152}$ Las ejecuciones de personajes más o menos relevantes en la vida de Roma, que sucedieron a la muerte del prefecto, tuvieran que ver o no con la supuesta trama conspirativa de Plauciano, lo que reflejaron sin ninguna duda fue la voluntad y actitud de Septimio de redirigir la situación. Al final se realizó una purga contra los partidarios y seguidores del prefecto, así como contra personajes influyentes susceptibles de convertirse en peligrosos para el poder. Tales parecen haber sido los motivos de la domus severiana a partir de enero del 205. Numerosos senadores y caballeros murieron en el 205 o poco después tras comparecer ante el tribunal del emperador. Las represalias cayeron sobre ambos bandos. Dion Casio cita algunos amigos y partidarios de Plauciano: el caballero egipcio Aelius Coeranus ${ }^{153}$ fue considerado confidente de Plauciano, ${ }^{154}$ al que el bitinio califica de parásito de Plauciano, fue procurator de libellis y miembro de un probable gabinete del joven Caracalla en tanto que corregente, fue castigado por haber predicho que Plauciano reinaría sobre la tierra y el mar y fue exiliado a una isla durante siete años. Sin embargo, pudo volver del exilio coincidiendo con el inicio del reinado de Caracalla y fue el primer egipcio admitido en el Senado romano cuando fue designado cónsul por este mismo emperador. ${ }^{155}$ Otro ecuestre represaliado fue Caecilius Agricola. Dion nos informa de su condena a muerte y posterior suicidio. Hay otros personajes a los que las fuentes no aluden pero que dado el corte que se produce en su carrera en el 205, podemos presumir que de alguna manera fueron represaliados. Fuluius Fuscus Granianus, senador. ${ }^{156}$ Debió estar relacionado con la familia materna de Septimio Severo y del propio Plauciano, y a ello debería sus cargos. ${ }^{157}$ De hecho, obtuvo la cues-

150. Sobre el exilio de los hijos de Plauciano ver D. C., LXxvII, 6, 3; Hdn., III, 13, 3 habla de exilio en Sicilia.

151. A. Mastino, «L'erosione del nome di Geta...», p. 55, nota 71, este autor cree que morirían en 211, inmediatamente después de la muerte de Septimio; A. Birley, Septimius Severus, p. 294 , n. 7 (inglés) (para la muerte en 212 meter autores nota 71 de la p. 55 de Mastino).

152. HDN., 4, 6, 3, cuenta que tras la muerte de Geta, Caracalla decidió eliminar a Plautilla y su hermano Hortensiano. D. C., LXXI, 1,1, asocia su ejecución a la de su preceptor Evodo y a la del confidente de Severo, Cástor, antes incluso de que tuviera lugar el asesinato de Geta. Cfr. Hdn., 3, 13, 3 y D. C., Lxxvi, 6, 3.

153. P.(¿) Aelius Coeranus. Su praenomen fue probablemente Publio, como el de su hijo que sí se conserva. : Окоќ, Septimius Severus et Senatores..., nota 122; PIR ${ }^{2}$ A161, cfr. J. P. Coriat, «Les préfets du prétoire...», p. 260; D. C., LXXVI, 5, 5 .

154. D. C., LXXVI, 5, 3-4.

155. D. C., Lxxvi, 5, 5 y LxxviI, 3, 3.

156. Fue quaestor y XV uir sacris faciundis en la celebración de los ludi saeculares de 204 (CIL VI $32327=I L S 5050 \mathrm{a})$.

157. D. OкоŃ, Septimius Severus et Senatores, p. 58. Provendría de África. M. Corbier, «Les familles clarissimes d'Afrique proconsulaire (Ier-IIIe siècle)», Epigrafia e ordine senatorio II (Tituli 5), Roma, 1982, p. 722, dice que era originario de Lepcis Magna; F. CHAusson, «Varietés généalogiques, II», pp. 149 y ss. Este último autor sugiere que el cónsul del 238, Fuluius Pius, podría ser su hijo. 
tura como candidatus Augustorum (Severo y Caracalla). También participó en los ludi saeculares como XV uir sacris faciundis. La falta de información a partir del 205 y su relación con Plauciano podría sugerir su caída. Domitius Florus que desempeñó ab actis senatus y no se convirtió en edil ${ }^{158}$ por su relación con Plauciano. ${ }^{159}$ Q. Anicius Faustus, que fue comandante de la Legión Númida III Augusta y que habría desempeñado un excelente trabajo en la frontera de África y que fue cónsul sufecto en el 198. Sin embargo, desaparece desde el 205 hasta el 217 en que retoma de nuevo su carrera, esta vez con Macrino, que igualmente estuvo ligado a Plauciano. Quintilus Plautianus, un significado senador que es mencionado por Dion Casio. ${ }^{160}$ Posiblemente se trate de M. Peducaeus Plautius Quintillus, cónsul ordinario del año 177, hijo del cónsul del 159, Plautius Quintillius y Ceionia Fabia, hermana del emperador Vero. ${ }^{161}$ Cabría la posibilidad de que Caracalla intentara anticiparse con el asesinato de «posibles» candidatos bien situados a sucederle, pero puesto que en este tiempo otros familiares de Marco Aurelio no sufrieron represalias, más bien parece que se trataría de algún tipo de participación en los hechos. ${ }^{162}$ Popilius Pedo Apronianus, cónsul en el 191 y procónsul de Asia en el 205, era también un miembro importante del Senado. Fue acusado porque se dijo que su nodriza había visto en sueños que accedería al trono imperial y que había utilizado prácticas mágicas para hacerlo realidad. Fue condenado in absentia puesto que se encontraba en Asia desempeñando su cargo. Es destacable el relato de Dion respecto a cómo se realizó la acusación en el Senado, cuando en el informe, realizado por el propio emperador, un testigo acusaba a un anónimo senador calvo. Es destacable la narración de Dion sobre el comportamiento de los senadores tras conocer este dato del informe y cómo se miraban unos a otros buscando un culpable sin pelo. El testimonio del escritor sobre sí mismo es elocuente al máximo: «me sentí tan desconcertado que me eché la mano a la cabeza palpándome el pelo». Tales eran los sentimientos y emociones de los senadores en momentos tan complicados. Las pruebas acusaban al senador Baebius Marcellinus, ${ }^{163}$ quien puesto en pie pidió ser identificado por el informante y cuando así se hizo fue sacado al foro y ejecutado sumariamente, hasta el punto de que ni siquiera el propio emperador conocía su condena ${ }^{164}$ Otro senador caído en desgracia fue Pollenius Sebenus, ${ }^{165}$ que fue acusado en el 206 de haber actuado improcedentemente durante su gobierno del Nórico. Precisamente fue su tío Polieno Auspex, amigo cercano del emperador, quien gracias a su mediación le salvó la vida pero no pudo evitar que

158. D. C., LXXVIII, 22, 2.

159. D. ОкоŃ, Septimius Severus et Senatores, p. 58.

160. D. C., LXXVI, 7, 3-4.

161. Ibidem, 59, confirmado por las inscripciones CIL VI 631= ILS 5084; CIL VI 2382b; CIL XIV 328=ILS 7022; CIL X 285 = I.I. 3, 1, 259; CIL XV 7360 citadas por Okoń.

162. Idem.

163. Edil curul en el 205 y posiblemente hijo de Baebius Caecilianus que fue legado de Pannonia Inferior.

164. D. C., LXXVI, 7, 3-9.

165. A. Daguet-Gagey, Septime Sévère, p. 357. 
fuera entregado por el nuevo gobernador Catio Sabino a los provinciales para que fuera procesado. ${ }^{166} \mathrm{El}$ exceso de celo en las damnationes memoriae llevó a situaciones como las de las arae encontradas en el santuario de beneficiarii de Osterburken. En dos de ellas, soldados de la XXII Primigenia que habían sido dedicadas el 15 de julio y el 26 de diciembre ${ }^{167}$ del año 203 con la data consular, con el segundo consulado de Publio Septimio Geta, hermano de Severo y el segundo de Plauciano, fueron borradas las datas consulares, el segundo en el 205 y el primero por error en el 212, posiblemente cuando fue raspada una tercera ara, ${ }^{168}$ del 15 de julio del 205 (Caracalla y su hermano Geta eran los cónsules). ${ }^{169}$ Los años 205-207 fueron de gran tensión sin comparación con el periodo 202-204 que marcó el cénit del poder de Plauciano.

A. Daguet-Dagey ha puesto en relación con los acontecimientos del 205 dos inscripciones, ya conocidas de antiguo, así como una serie de emisiones monetales. La primera inscripción procede de Sicca Veneria ${ }^{170}$ y la segunda de Éfeso. ${ }^{171}$ El epígrafe africano fue elevado por los decuriones de Sicca y se trata de una ofrenda a I.O.M.C., fechada entre el 1 de enero y el 9 de diciembre del 208. Las últimas líneas son verdaderamente interesantes para la teoría propuesta por esta investigadora: ob conseruatam eorum sa / lutem, detectis insidiis / hostium publicorum, / d(ecreto) d(ecurionum) p(ecunia) p(ublica). Las preguntas son evidentes: ¿a qué insidias se refieren? ¿Quiénes son los enemigos públicos? Después hacer repaso y de analizar situaciones comparables en la historia de Roma, como Avidio Cassio, Maximino el Tracio, la conjuración de Catilina o el propio bandolero Bullas que entre el 205 y el 207 mantuvo en jaque a la península itálica. Respecto a la fecha relativamente tardía de 208 , en relación con los acontecimientos del 205, trae el paralelismo de la situación de Sejano, que fue eliminado por Tiberio en el 31 d. C. y, siguiendo a Tácito, ${ }^{172}$ las represalias seguían tres años después. El caso de Éfeso, una inscripción votiva bilingüe ofrecida por Helicón, liberto imperial. En ella se alude a que la familia imperial fue salvada merced a la prouidentia deorum. Las fechas no se pueden concretar, se data entre el 198-210. La inscripción menciona...spes] / parricidiales insid[iatorum sustulerunt]. En ella, como vemos, también se habla de insidias, y spes parricidiales (el haber intentado Plautiniano atentar contra su yerno y su propio consuegro). Definitivamente estas alusiones para la investigadora francesa hacen alusión a los hechos del 205 con un eco posterior en Asia. Para otros autores esta inscripción podría ponerse

166. D. C., lxxvi, 9, 2-4. A. Birley, Septimio Severo...pp. 244-245; A. Daguet-Gagey, Septime Sévère Roma, p. 357.

167. $A E, 1996,1161$ y 1155

168. $A E, 1996,1153$.

169. S. Benoit, «Titulatures impériales et damnatio memoriae. L'enseignement des inscriptions martelées», Cahiers Glotz, xv, 2004, p. 183, nota 32.

170. $C I L$ VIII, $1628=I L S 429$.

171. CIL III, $427=I L S 427$.

172. Ann., 6, 38, 1. 
en relación solo con el proceso de Apronianus. ${ }^{173}$ Propone considerar que los dos epígrafes, el de Sicca y Éfeso, hacen alusión a los acontecimientos que arrastraron a la domus Augusta a partir del 205 y que el de Asia podría estar asociado también a los sucesos de la condena de Pedo Apronianus. En segundo lugar, centra su atención en algunas emisiones monetarias, concretamente aquellas que fechadas en el 207, aluden a Septimio y sus dos hijos como restitores $u r b i s^{174}$ y que harían alusión a los acontecimientos desarrollados entre el 205-207. Si bien es verdad que la fórmula fue utilizada en el 200-201, que podrían tener que ver con la «pacificación» tras la derrota de Clodius Albinus y la persecución de sus partidarios, reaparece de nuevo ahora una época de relativa paz tras el convulso periodo del 205-207 sobre todo con el asunto de Plauciano y también con el del bandido Bullas y el asunto del procónsul de Asia Apronianus. En el 207 el emperador celebra sus quindecennalia y las decennalia de Caracalla. Asimismo, los trabajos de P. V. Hill parecen confirmar que en el año 207 aparecen una serie de leyendas monetales que nos hablan de un contexto en el que desde el poder imperial se propaga el final de los problemas y una era de estabilidad. ${ }^{175}$

\section{ConClusiones}

Hemos repasado la figura de Pluciano que ilustra sobre los límites del poder y su capacidad para imponerse en la escena política. Propulsado como nunca antes lo había sido nadie en el mundo romano gozaba de la amistad y confianza del emperador y utilizó los poderes y beneficios que le otorgaban su cargo y su cercanía a Septimio. Finalmente, el heredero al trono, su propio yerno, puso término brutal a su ambición cuando fue eliminado acusado de haber tramado una conjura contra Septimio y Caracalla. Sufrió la denominada damnatio memoriae, acorde a su poder, no se ha conservado ningún retrato, y citando de nuevo a Quevedo, a Plauciano, al que la vista calificó de estrella, finalmente los acontecimientos desmintieron sus luces en humo y ceniza.

173. J. P. MARTin, Prouidentia deorum. Recherches sur certains aspects religieux du pouvoir impérial romain, Roma, 1982, pp. 394-400.

174. A. DAguet-GAgEY, «Septime Sévère et ses fils, restitutores Vrbis. La personnalisation des mérites impériaux», RN, 2004, pp. 175-199.

175. Cf. P. V. HilL, The Coinage of Septimius Severus and his Family of the Mint of Rome, A. D. 193-217, Londres, 1977, pp. 24-26. 